
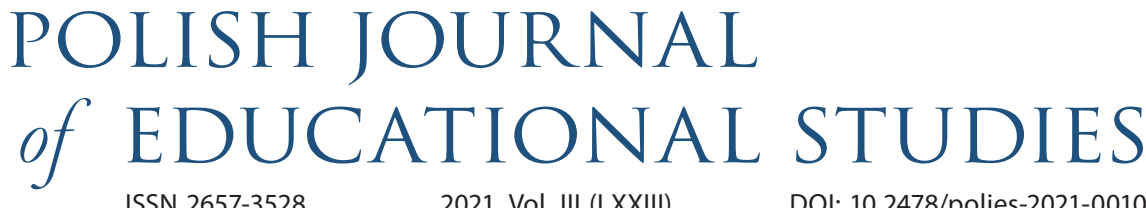

\title{
Social Networking Platforms and Classroom Culture
}

\author{
Thi Hien Quyen Van', James Underwood ${ }^{2}$, and Li Tai ${ }^{3}$
}

\begin{abstract}
This article investigates how social networks affect classroom culture in secondary schools. It combines personal reflections from us as professionals, who have worked in schools and in universities in a range of different countries and contexts, with the use of research written over the last decade into this area. Stylistically this article is a conceptual article - it has a strong reflective element and its purpose within the wider academic and professional community is to generate discussion among professionals rather than to find definitive conclusions. Classroom culture is commonly divided into four dimensions: group attitudes and behaviours toward learning, group attitudes and behaviours towards interaction with peers, teacher attitudes and behaviours towards students and instruction, and parental behaviours towards children and the teacher. This framework underpins this article. Even though social networks play an important part in young students' lives globally, most studies into the usage of social networks for education have been conducted at the level of higher education and only a few studies focus on school level. This paper therefore focuses on school level usage and possibilities. The paper concludes that whatever our views on social media, the reality is that Facebook and its many counterparts are part of current culture and are already being used by many teachers globally as learning tools. Given that they can have both negative and positive impacts on classroom culture and are becoming an inevitable part of many young students' lives, schools have limited options. The first one is to ban social networks to make sure that there are no consequences, and this is the case in a wide range of systems and jurisdictions. However, other approaches, which can be a frequently found globally,
\end{abstract}

1 University of Northampton, United Kingdom

2 University of Northampton, United Kingdom E-MAIL: james.underwood@northampton.ac.uk ORCID: 0000-0001-9351-2408

3 University of Cambridge, United Kingdom ORCID: 0000-0002-4936-7706 
include a managed approach to Facebook - with course, class or even teacher pages - often entirely separate to the individual teacher's personal page.

\section{KEYWORDS:}

Facebook, social media, classroom culture, student teacher relationships, classroom dynamic.

\section{Introduction}

The first two decades of the $21^{\text {st }}$ century have seen a boom in the use of social networks. Globally social networks such as Facebook and Twitter have become a part of the personal and professional lives of students and teachers alike. This article investigates how these networks affect classroom culture in secondary schools. The aim of this article is to present an interlinked account of our professional experience and current research literature in order to engage fellow professionals and practitioners in debate and discussion. This article therefore combines personal reflections from us, as professionals who have worked in schools and in universities in a range of countries and contexts, with the use of research written over the last decade into this area. The use of social media within schools and classrooms is a contentious area. There are significantly different cultural norms internationally and there are also often individual professionals with differing views working within the same school or local area. Debates are often interlinked to over lapping debates, within sensitive areas, including those regarding: risk-taking, child-protection, teacher privacy and concepts of professionalism, Viewpoints are therefore often strongly held and passionately defended. The aim of this article is to facilitate constructive debate. We are already aware that this article will specifically be used in several schools on leadership days in the UK and in Vietnam - as well as we hope, in potentially other contexts. In brief: stylistically this article is a conceptual paper or 'thought piece' (Underwood, et al., 2020) - it has a strong reflective element and its purpose within the wider academic and professional community is to generate discussion among professionals rather than to find definitive conclusions.

Classroom culture is a slippery concept that has been understood and interpreted in different ways. However, according to all commonly used models for understanding it - classroom culture includes, at its heart, the interactions, values and behaviours of the students and teacher(s). It also often involves understanding this within the context of the wider community including parents (Glover \& Coleman, 2005). One useful and frequently cited framework for understanding classroom cultures developed by Cavanagh and Waugh (2004) divides classroom culture into four elements: group attitudes and behaviours toward learning, group attitudes and behaviours towards interaction with peers, teacher attitudes and behaviours towards students and instruction, 
and parental behaviours towards children and the teacher. This framework underpins this article. Where definitions of classroom culture diverge, and conflicting models emerge, tends to be regarding the relationship between student learning outcomes and classroom culture. On the one hand, students' academic achievements can be considered to be a part of classroom culture because they affect the students' satisfaction with their learning experience, and therefore provide them with motivation. On the other hand, student learning outcomes can be seen as a result of a positive classroom culture but not an aspect of the classroom culture itself (McMahon, 2021). In this article, student academic performance will be examined from both positions and this conflict used as a lens for further exploration

\section{Social networks}

For the purpose of this article a social network is defined as: a website or app that allows people to communicate and share information using a computer or mobile phone. Based on this definition in 2021, the world's most popular social networks included: Facebook, WhatsApp, Instagram, Twitter and TikTok (Statista, 2021).

The majority of research into social networks and education has focused on the use of Facebook, which is the mainstream social networking platform, most frequently used for educational purposes (Qadi, 2020; Su \& Chen, 2020). This is for the following reasons: firstly, its scale, Facebook has a massive and increasing number of users, 2.4 billion (Statista, 2021). Secondly, its established status - along with Twitter it is the the only major social network platform founded prior to 2010. Third, its design - Facebook users can broadcast their opinions, share their ideas and update their status on their own page (unlike Whatsapp). It is also text friendly rather than image based (unlike Instagram or TikTok); and through newsfeeds and group pages users can also keep updated with the latest trends and with popular topics around the world. Through these design features Facebook manages to keep users highly active on its platform. However, although most research referred to in this article involved the use of Facebook, the points raised and conclusions drawn are more widely applicable to the potentials and challenges of using other social networking sites.

\section{Teenagers and social networks}

Although the majority of Facebook users are over 18 years old, there are still a large number of teenage users from 13 to 18 years old using them. Research into usage by this age group in particular has revealed that topics discussed among teenagers in social networks primarily concern their daily life stories such as relationships, school and friends (Argamon et al., 2017). Furthermore, compared to adults, teenagers spend more time on social media. Research from several years ago, reveals that, even in an early stage in their emergence, social networks became, in the perception of teenagers 
themselves, the main tool through which they could express their opinions (Shapiro \& Margolin, 2014). However, even though social networks play an important part in young students' lives, most into the usage of social networks for education have been conducted at the level of higher education and only a few studies focus on school level (Van Den Beemt et al., 2020).

It is also the case that studies at college level have focused largely on the deliberate use of social media for educational purposes. These have included research into using social networks, especially Facebook for: language teaching, communication between faculty and teachers, building learning communities, and for developing reading skills (Giannakis, 2020). They have also tended to focus on aspects of these sites that have been modified by teachers to fulfil these specific pedagogical purposes (Madrigal \& Manna, 2020). This article therefore responds to this research gap by also examining the relationship between social network pages, which are not designed for pedagogical uses and the impacts they have on the classroom culture of teenage students at school level.

\section{Social networks and four dimensions}

In this section of this article social networks and the relationship to classroom culture is examined from four angles: students' attitude and behaviours toward learning, teacher-student relationships, student-student relationships, and (more briefly) parents' attitudes and behaviour towards their child and the teacher.

\section{Students' attitude and behaviour toward learning}

If student engagement in a learning context is understood as the time and effort spent on educational activities then a number of studies have shown that social networks such as Facebook and Twitter can significantly contribute to increasing students' engagement in studying. Firstly, they can increase students' engagement by providing opportunities for students to communicate with teachers outside of the physical and time limitations of the classroom (Qadi, 2020); and secondly they are often perceived positively by students, as it makes it easier to ask questions about the lesson content; and they allow quieter students to express their opinions and ask questions by sending messages to teachers after lessons (Su \& Chen, 2020). This possibility of using textchat to include students who may not usually contribute, through inhibition or other reasons, in class, is found in several studies to be a particularly positive aspect (ibid).

Secondly, social networks allow students to create an online community thanks to group-creating functions. These online communities have been shown to increase interaction between students when they have been used for class reminders, book 
discussions, and study groups (Rozina et al., 2020). Research conducted even during the early years of the development of social media revealed that it is the sense of involvement created by this online community that engages and motivates students with regard to their lessons (Evans, 2013). Social networks increase students' engagement and motivation by providing them with a tool to communicate with teachers and a virtual environment to engage with the lessons that is different from the physical classroom. This online environment transcends the time and physical limitations of the traditional classroom, enabling students to participate more regularly in learning activities, thereby creating a positive class dynamic.

However, other research has suggested that social networking via such platforms as Facebook and others can be addictive (Buzzelli et al., 2016), leading teenage students to spend long hours on them. There is, therefore, a risk that social networks may distract them from taking part in learning activities. This is a real possibility because social networks such as Facebook lack any distinction between entertainment and intellectual engagement and therefore have built within them distractibility. A study by $\mathrm{Li}$ (2020) showed that the main purposes of students using social networks was to check their friends' status updates and personal messages, while they were least used for educational purposes and applications. However, the fact that young students use social networks mostly for non-educational purposes does not explain how these social networks actually affect learning and studying in the physical classroom, nor does it necessarily imply that they have a negative impact. Li's (2012) study into Facebook usage was carried out in a situation in which Facebook was not intentionally used as an educational tool. It is therefore debatable whether Facebook or other social networking sites would distract students from learning when these social networks are intentionally used for teaching and learning purposes.

\section{Student-student relationships}

Social network platforms allow users to describe different attributes about themselves such as their birthday, hometown and other personal information such as favourite singers, movies or activities. Facebook particularly emphasizes this within its design. They also allow users to quickly and conveniently interact with friends and classmates on a regular basis. Additionally, friends on these platforms can keep updated on each other's daily activities. In this way, students can potentially develop friendships based on understanding - both inside and outside the classroom (Li, 2020). Students can therefore stay close to each other not only because they can post updates about their lives on social networks, but also because they can use these sites as a place to share their mutual interest in their studies, meaning that they can create an online learning community beyond the confines of the traditional classroom (Bacaksiz et al., 2020). 
For example, Facebook allows users to create different groups or communities on its platform. Students can use this function to create groups of interest for a subject, group work or hobby. What is special about these groups is that they can connect students not only in the same classroom but also from different schools (Sosa, et al., 2020). Other apps and sites such as Whatsapp also have this capability. This close connection among students inside and outside the classroom can enhance their friendships and create a positive dynamic for the classroom climate and as a result, academic performance could be indirectly improved (Tsai \& Liu, 2015).

However, this breaking of boundaries can also lead to crossing boundaries that keep students safe. The development of social networking sites has created a new environment in which bullying can thrive, resulting in the presence of cyberbullying. Social networks have become one of the main platforms for cyberbullying (Mishna et al., 2020). Similar to traditional bullying, cyberbullying is "deliberate, repeated, and hostile behaviour intended to harm others" (Jones \& Scott, 2012). This behaviour can be done directly to the victim by sending direct messages for example, or indirectly, by spreading rumors. However, compared to traditional bullying, cyberbullying can become more powerful and dangerous because technology allows it to happen beyond the school walls and school hours, meaning that the victims "never feel safe from the bully" (Jones \& Scott, 2012).

Additionally, cyberbullying is hard to intercept and prevent because it happens in cyberspace, which is "quicker, more comprehensive, and almost unstoppable and unavoidable" (Jones \&Scott 2012). It is also worth noting that cyberbullying typically hurts victims emotionally rather than causing direct physical damage. Therefore, it is difficult for teachers and parents to identify cyberbullying victims if they remain quiet. Anyone can be a victim of cyberbullying, and school teenagers are especially vulnerable because of their high frequency in using social networks and their lack of maturity.

Cyberbullying has a negative effect on students' mental development and health, which possibly affects classroom dynamics and values. A study by Ging and O'Higgins (20200 showed that academic achievement, worldwide, is a frequently found factor in bullying. A student with high academic results is likely to become a victim of cyberbullying from other classmates. Students can become the target of cyberbullies if they actively contribute to the lesson. As a result, the victims' academic performance drops and the dynamics of a class changes when a fear of being bullied stops students from contributing to the lesson. Other factors that result in students being bullied online include students' sexual orientation and race (Mishna et al., 2020). This raises the question of classroom values, specifically how to establish a class where students are being valued for who they are when so much class interaction may be invisible to the teacher and online. 
It is important to note that cyberbullying is not the only risk that young students have to face when using social networking sites. There are other potential risks such as peer pressure, depression, and privacy concerns over stalking or exposure to harassment and sexual content (Ging \& O'Hioggins, 2020). These potential risks can cause significant physical and mental damage to young students, which can affect their learning and studying and eventually affect classroom culture. Given that young students are a vulnerable user group of social networks, the roles of parents and teachers in guiding them becomes more important.

\section{Student-teacher relationships}

In many regions and systems teachers use Facebook and other social media sites to interact with school age students, whilst in others this is strictly forbidden. This diversity is interesting in itself and presents challenging questions for teachers interacting within a globalized society. A study by Asterhan and Rosenberg (2015) on teacherstudent contact on Facebook found that teachers worldwide use this type of social network for three different purposes. The first one is an academic instructional purpose, which means that teachers use Facebook to extend learning beyond the traditional classroom and to provide an organisational infrastructure for school activities. Facebook, in this situation, becomes both a means of communication and a study environment for students. The second purpose of teachers connecting their students on social networks is for psycho pedagogical purposes. With this purpose, social networks become a tool for teachers to obtain insight about students' well-being and to monitor and patrol the virtual atmosphere, keeping students away from potential risks such as cyberbullying, the distribution of sexual content or creation of hate groups. The last one is a social relational purpose, which means that teachers use Facebook to get to know their students as people and to deepen their relationship. On social networks, the sense of hierarchy decreases and the boundary between students and teachers is blurred from the academic instructional purpose to the social relation one.

Numerous studies show that positive teacher-student relationships on social networks can lead to positive academic outcomes and a positive atmosphere in class (Asterhan \& Rosenberg, 2015). Social network platforms like Facebook allow users to self-disclose by sharing information, telling personal stories and conveying personal beliefs which can enhance the psychological closeness between teachers and students. Therefore, students who check their teacher's profile on a social network may feel more comfortable communicating and asking questions of the teacher. Managed self-disclosure, family photos or stories for example, by a teacher on social networks may help to create positive student teacher relationships (Peeters, 2019). However, such interactions on facebook also carry risks. 
Student-teacher interaction on social networks is a blurry shifting boundary (Asterhan \& Rosenberg, 2015). Whilst teacher-student relationships on social networks can have a positive effect on classroom culture, they also carry hidden risks to teachers' authority and status. Firstly, does "befriending" on social networks like Facebook mean being "friends" in the physical classroom, even when the Facebook site is a professional closed space and not a personal site? (Asterhan \& Rosenberg, 2015). Because the majority of Facebook pages are friendly, informal and intimate - the use of the platform at all risks creating an expectancy that usual classroom boundaries will not be in place (Hoi \& Hang, 2021). Secondly, any level of self-disclosure on social networks can put pressure on teachers' status inside classroom. An inconsistency in self-disclosure on social networks and the teacher's actual teaching style might create unmet expectation among students (Thunmann \& Persson, 2018). Additionally, if they do not agree with the beliefs that their teachers share on social network, there is a possibility that teenage students will have a negative reaction against their teacher in class (Aloudat et al., 2019). Although, social networks can deepen the relationships between teacher and students, they can also create pressures and expectations on teachers, even when they are not using personal pages but are using pages designed for education and professional interaction.

Teachers' responsibility and well-being should also be considered when examining the relationship between social networks and classroom culture. In the first situation, if social networks such as Facebook are intentionally used by other colleagues as a learning tool, there is a risk that it becomes an expectation that teachers will use these social network platforms, potentially creating high levels of professional discomfort for some (Hershkovitz \& Forkosh, 2019). Unlike traditional lessons, Facebook and Twitter operate beyond school hours and outside school walls, allowing users to work on them 24/7 potentially intruding into a teacher's right to privacy and to having boundaries to their working day. Although Facebook and other sites are becoming increasing popular, there are still people who refuse to use them and even if the teacher uses social network accounts in their personal time it is not a reasonable expectation that they do the same as regards their students and colleagues (Hanell, 2017).

In the situation, when Facebook and Twitter are not used as a learning tool, there is the issue of the extent to which the teachers privacy can be protected. Specifically, in many countries a teacher can be at risk of losing their job depending on what they choose to post. One of the solutions for these concerns is to ask teachers to create professional Facebook and Twitter accounts, to be used for working purposes only. Teachers would then be limited with the content of posts and pictures they upload on social networks. This solution might answer the questions about teachers' image on social network but cannot yet solve the problem of privacy and responsibility or pressure on teachers' time (Borecki \& Aydin, 2020). 


\section{Social networks and academic performance}

Alhough social networks can increase students' engagement and motivation, it is still debatable whether student's academic performance can be improved by social networks or not. Academic results can certainly be improved by enhancing interactions between students (Lai, 2016) and increasing active involvement with the learning content (Smith, 2014). However, there is no conclusive evidence that social networks impact directly on academic results either positively or negatively. This is in part because academic outcomes can be improved by a multiplicity of factors and also because much social and professional interaction in schools is still in the real space of the classroom (Van Den Beemt et al., 2020).

However, when social networks like Facebook and other sites are intentionally used as a learning tool, they might contribute to the improvement of academic results. Noticeably, case study research has reported that social media sites have helped improve students' learning outcomes in foreign languages and writing classes when they have been used as a tool to support the learning process (Lee, Koo, \& Kim, 2016). On the other hand, in qualitative, perception studies. teachers have reported that Facebook and other similar sites cause distraction and shorten attention span among students, which lowers their learning results (Marked et al., 2017). It can be seen that even when social networks like Facebook are used as learning tools, the findings presented in different studies vary. This might be because the complexity of schooling in which secondary and high school students learn different subjects over the course of one academic year cannot be easily reflected by case study research. It might also be because the ways teachers and students use social networks as a learning tool differ.

\section{Social networks and parents' attitudes towards students and teachers}

The relationship between social networks and parents' attitudes towards students and teachers is an under-researched area. Parents do seem to have a direct influence on classroom culture through social networks. They can play the role of mediators, who control the phones and the timing and usage of social networks by their child. This is possibly why most research is conducted at college level because students have more autonomy in using social networks. In terms of the relationship between teachers and parents, there may be concerns about teachers' self-disclosure on social networks, specifically to what extent a teacher should reveal information about their personal life on social networks (Alpidat et al., 2019). This is important particularly in some Eastern countries where teachers are limited with certain moral standards and manners. However, there is also a possibility that social networks can increase parental involvement in their children's schooling and enable parents to communicate more actively with teachers. 


\section{Model of the relationship between social networks and classroom culture}

The relationship between social network platforms such as Facebook and classroom culture is complicated. They can have both a positive and a negative influence on classroom culture. Below is a graph describing this relationship.

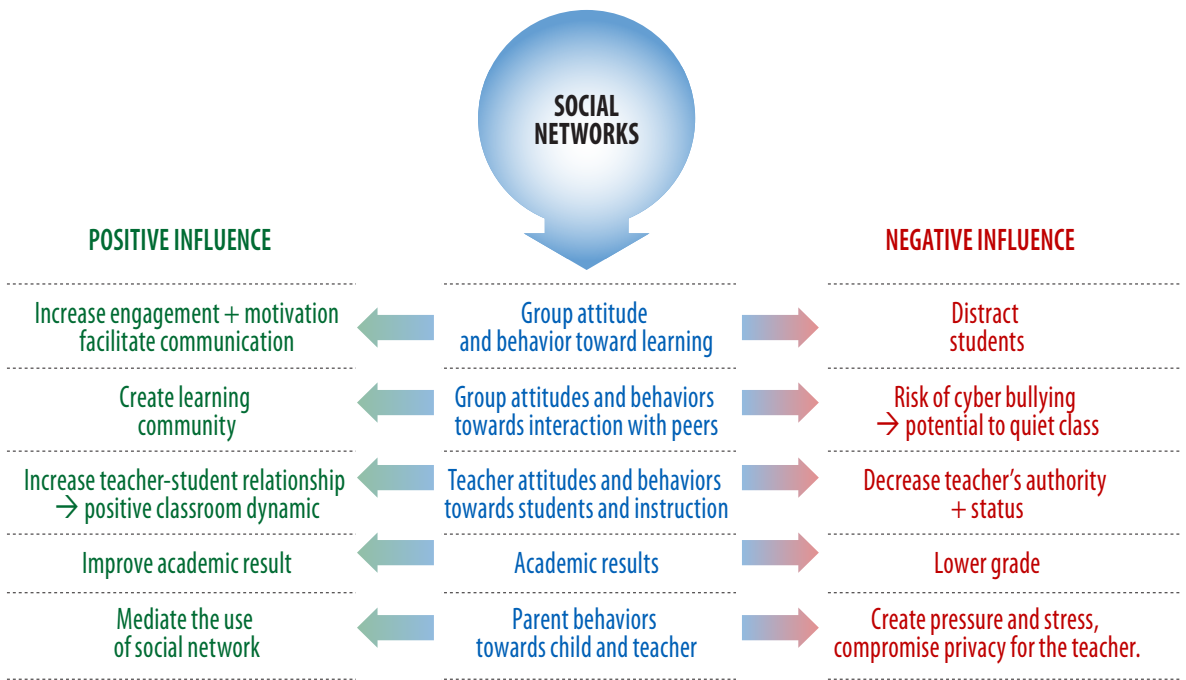

Graph 1. Relationship between social networks and classroom culture

\section{Conclusion}

Whatever our views on social media, the reality is that Facebook and its many counterparts are part of current culture and are also already used by many as learning tools. Teachers from different countries and systems depending on their own background often find themselves equally surprised that in some contexts these sites are widely used within schools or conversely that they are effectively banned. Regardless of the context: social network platforms like Facebook can have real effects on different aspects of classroom culture. Research has identified positive influences on classroom culture, such as improving students' motivation and engagement and deepening the professional relationship between students and teachers. On the other hand, these social network platforms hide many risks; the line between positive and negative influences is very blurry; and positive effects can turn into negative ones rapidly or can even be interpreted differently in different cultural contexts.

Globally given that they can have both negative and positive impacts on classroom culture and are becoming an inevitable part of many young students' lives, 
schools have limited options. The first one is to ban social networks to make sure that there are no consequences, regardless of any the benefits these platforms may be able to bring. In many contexts globally teachers are barred from 'friending' teachers on Facebook. However, other approaches worldwide include a managed approach to facebook - with course, class or even teacher pages - often entirely separate to the individual teacher's personal page (Daly, 2019).

The purpose of this article was to open up discussion among professionals by presenting this diversity and a summary of some of the underpinning arguments for these choices. Despite their online nature, the impact that these sites have on us are real. The pain of cyberbullying is as real as the positive community building that these sites can facilitate.

\section{Refereneces}

Aloudat, A., Al-Shamaileh, O., \& Katina, M. (2019). Why some people do not use facebook. Social network analysis and mining, 9(1). DOI: 10.1007/s13278-019-0564-z.

Asterhan, C., \& Rosenberg, H. (2015). The promise, reality and dilemmas of secondary school teacher-student interactions in Facebook: The teacher perspective. Computers \& Education, 85(C), 134-148.

Bacaksiz, F., Eskici, G., \& Seren, A. (2020). "From my Facebook profile": What do nursing students share on Timeline, Photos, Friends, and About sections? Nurse education today, 86(1), 104326-104326.

Börekci, R., \& Aydin, S. (2020). Foreign language teachers' interactions with their students on Facebook. Computer assisted language learning, 33(3), 217-239.

Buzzelli, A., Holdan, E., Rota, D., \& Mccarthy, J. (2016). Utilizing Twitter for Concept Learning. Teaching education, 12(1), 64-76.

Cavanagh, R., \& Waugh, F. (2004). Secondary school renewal: The effect of classroom learning culture on educational outcomes. Learning Environments Research, 7(3), 245-269.

Daly, L. (2019). I Have My Students Create "Fakebook" Profiles for Historical Figures. https:// www.weareteachers.com/fakebook-lesson-plan/

Evans, B. (2013), Enhancing Undergraduate Teaching and Feedback using Social Media - an Engineering Case Study. Engineering Education, 8(2), 44-53. DOI: 10.11120/ ened.2013.00015

Giannakis, C. (2020). Facebook in tertiary education: The impact of social media in e-Learning. Journal of university teaching \& learning practice, 17(1), 23-36.

Ging, D. \& O'Higgins, N. (2020). Cyberbullying, conflict management or just messing? Teenage girls' understandings and experiences of gender, friendship, and conflict on Facebook in an Irish second-level school. Feminist media studies, 16(5), 805-821.

Glover, D. \& Coleman, M. (2005). School climate, culture and ethos: interchangeable or distinctive concepts? Journal of Inservice Education, 31(2), 251-72. 
Hershkovitz, A., \& Forkosh, A., (2019). Students' Perceptions of Benefits and Drawbacks of Facebook-Connections with Teachers. Interdisciplinary journal of e-skills and lifelong learning, 15(1), 1-20. DOI: 10.28945/4180.

Hoi, V., \& Hang, H. (2020). Understanding students' behavioural intention to use facebook as a supplementary learning platform: A mixed methods approach. Education and information technologies, 26(5), 5991-6011.

Lai, C. (2016). Training nursing students' communication skills with online video peer assessment. Computers and Education, 97, 21-30. DOI: 10.1016/j.compedu.2016.02.017.

Lee, J., Koo, Y., \& Kim, M. (2016). Enhancing problem solving skills in science education with social media and an e-collaboration tool. New Educational Review, 43, 248-259. DOI: 10.15804/tner.2016.43.1.21.

$\mathrm{Li}, \mathrm{X}$. (2020). Are All "Friends" Beneficial? The Use of Facebook and WeChat and the Social Capital of College Students in Macau. SAGE open, 10(4). DOI: 10.1177/2158244020963 614.

Madrigal, E. \& Mannan, R. (2020). pathCast: An Interactive Medical Education Curriculum That Leverages Livestreaming on Facebook and YouTube. Academic medicine, 95(5), 744-750.

Mishna, F., Schwan, K., Birze, A., Van Wert, M., Lacombe-Duncan, A., McInroy, L., \& AttarSchwartz, S. (2020). Gendered and Sexualized Bullying and Cyber Bullying: Spotlighting Girls and Making Boys Invisible. Youth \& society, 52(3), 403-426.

Peeters, W. (2019). The peer interaction process on Facebook: a social network analysis of learners' online conversations. Education and information technologies, 24(5), 31773204.

Rozina, A. Suria, S. Nurul, I. \& Nusrat, Z. (2020). Using Facebook to enhance student engagement in undergraduate sociology classes at Bangladeshi colleges. International Journal of Research in Business and Social Science, 9(6), 213-223.

Shapiro, L.A.S., \& Margolin, G. (2014). Growing up wired: Social network- ing sites and adolescent psychosocial development. Clin. Child Family Psychol. Rev., 17(1), 1-18.

Smith, D. (2014). iTube, YouTube, We Tube: Social media videos in chemistry education and outreach. Journal of Chemical Education, 91, 1594-1599. DOI: 10.1021/ed400715s.

Sosa, P., Carrazoni, G., Gonçalves, R., \& Mello-Carpes, P. (2020). Use of Facebook groups as a strategy for continuum involvement of students with physiology after finishing a physiology course. Advances in physiology education, 44(3), 358-361.

Su, Y., \& Chen, H. (2020) Social Facebook With Big Six Approaches for Improved Students' Learning Performance and Behavior: A Case Study of a Project Innovation and Implementation Course. Frontiers in psychology, 11(1), 1166-1166

Takacs, Z., Swart, E., \& Bus, A. (2015). Benefits and pitfalls of multimedia and interactive features in technology-enhanced storybooks: A meta-analysis. Review of Educational Research, 85, 698-739. DOI: 10.3102/0034654314566989.

Thunman, E., \& Persson, M. (2018). Ethical dilemmas on social media: Swedish secondary teachers' boundary management on Facebook. Teacher development, 22(2), 175-190. 
Tsai, H.-C., \& Liu, S.-H. (2015). Relationships between time-management skills, Facebook interpersonal skills and academic achievement among junior high school students. Social Psychology of Education, 18(3), 503-516. DOI: 10.1007/s11218-015-9297-7.

Underwood, J., Kowalczuk-Walędziak, M., \& Barrow, J. (2020). Using qualitative research in an international context. Culture and Education, 2(128), 156-173.

Qadi, A. (2020). The Role of Facebook in Enhancement of Undergraduates' Receptive Skills at a Saudi University. English language teaching, 14(8), 19-32.

Van Den Beemt, A., Thurlings. M., \& Willems, M. (2020) Towards an understanding of social media use in the classroom: a literature review. Technology, Pedagogy and Education, 29(1), 35-55. DOI: 10.1080/1475939X.2019.1695657. 